\title{
Diverting colostomy induces mucosal and muscular atrophy in rat distal colon
}

\author{
P Kissmeyer-Nielsen, H Christensen, S Laurberg
}

\begin{abstract}
The progress of adaptive changes in the left colon after diverting colostomy was studied in rats using stereological techniques. Standardised segments of left colon proximal and distal to the colostomy was examined after $0,1,2,4$, or 12 weeks. In excluded colon the mucosal weight was reduced by $37 \%(p<0.01)$ and the luminal surface area by $47 \%(p<0.01)$ after four weeks and reached a steady state at this point of time, as no further reduction was seen from 4 to 12 weeks. The number of proliferating crypt cells was determined immunohistochemically after in vivo labelling with bromodeoxyuridine and was compared with the total number of colonocytes. Total bowel rest leads to a reduction in the number of proliferating epithelial cells and not to a reduced average life span. The weight of the muscularis propria decreased by $32 \%$ after four weeks $(p<0.01)$ and by $48 \%$ after 12 weeks $(p<0.001)$, whereas the weight of the submucosa was unchanged. No adaptive changes were found in segments proximal to the colostomy. These results show that the wall composition of defunctioned colon in rats is radically changed resulting from a mucosal and muscular atrophy, and from a reduction in luminal surface area.

(Gut 1994; 35: 1275-1281)
\end{abstract}

Multistage procedures that include a temporary colostomy have become the standard approach in the surgical treatment of many emergency and some elective colonic conditions. Although the performance of a colostomy later followed by colostomy closure \section{December 1993 \\ Surgery L, University Hospital of of Aarhus, and Lab, University of Aarhus, DK-8000 Aarhus C, Denmark $\mathrm{H}$ Christensen \\ Correspondence to: Dr Kissmeyer-Nielsen, Surgical Research Unit, Department of Surgery L, Amtssygehuset, University Hospital of Aarhus, DK- ember 1993}
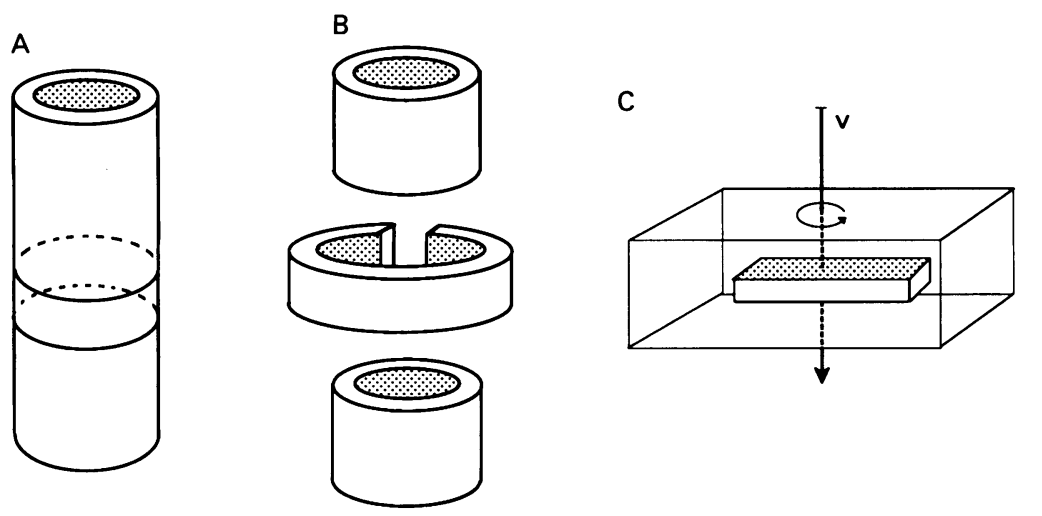

Figure 1: Embedding procedure used for vertical sections. ( $A$ and $B)$ : The colonic segments are cut out transversely into $5 \mathrm{~mm}$ rings and opened; $(C)$ : when the flat specimens are embedded in the plastic block they are free to shift sideways and to rotate around its vertical axis (v), which is kept at a right angle to the horizontal plane. is regarded as a safe procedure, the latter is still associated with a significant rate of morbidity and mortality. ${ }^{12}$ The complications include anastomotic leak, faecal fistula, and anastomotic obstruction. ${ }^{3}$ When the faecal stream is surgically divided, the luminal environment and the mechanical stimulation of the colon is radically changed. Although complications after colostomy closure may be related to trophic changes in the defunctioned bowel wall only few studies have been performed to characterise the overall colonic response to surgical defunctioning.

Luminal bulk is considered to be important for normal mucosal growth in the entire gastrointestinal tract. Profound mucosal hypoplasia has been found in biopsy specimens taken from the defunctioned rectum in humans, ${ }^{4}$ and in rat colon reductions in the mucosal cell proliferation and mucosal mass have been shown after total parenteral nutrition, ${ }^{5}$ fasting, ${ }^{6}$ and faecal diversion. ${ }^{7-9}$ The morphometric information in these studies was, however, obtained mainly from isolated crypts, and consequently they did not fulfil modern stereological requirements regarding uniform specimen sampling. ${ }^{10}$ Blomquist $e t$ al has shown a decrease in collagen synthesis and collagen content of the entire wall of excluded colon in rats. ${ }^{11}$ These data show that the atrophic changes occur in all layers after defunctioning the large bowel, but at the present no morphometric information exist to support these findings.

The aim of this experimental study was, by means of new and unbiased stereological techniques, to investigate and quantify changes in the morphometry of the entire bowel wall after faecal diversion of the distal colon.

\section{Methods}

ANIMALS

Three months old female Wistar rats (Møllegaard, Ejby, Denmark), weighing 200-240 g at the start of the experiment, were used. The animals were housed in air conditioned cages with a 12 hour light cycle and had free access to normal pellet food (Altromin diet 1324, Chr Pedersen Ltd, Ringsted, Denmark) and tap water.

\section{SURGERY}

A midline abdominal incision was performed under general anaesthesia (pentobarbital $50 \mathrm{mg} / \mathrm{kg}$ body weight intraperitoneal). A soft plastic catheter (urethral pressure catheter, outside diameter $0.8 \mathrm{~cm}$, Uno plast Ltd, 


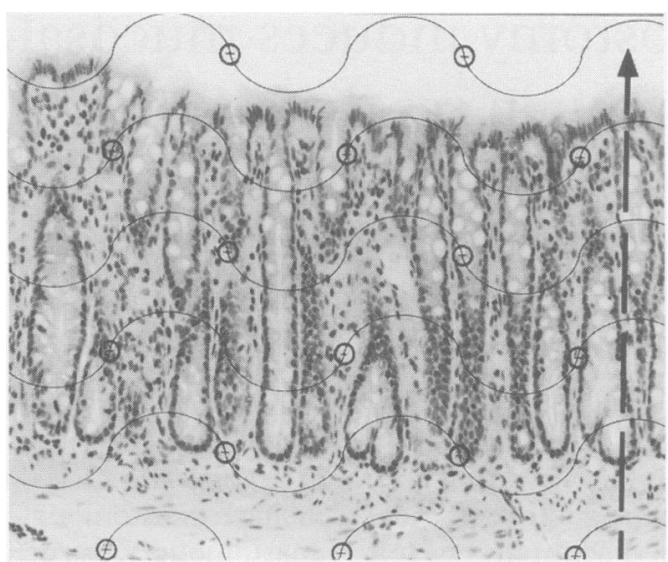

Figure 2: Vertical section of a colonic specimen at day 0 projected onto a cycloid test system for estimating surface area of the epithelial-lamina propria interface. (Van Gieson, original magnification $\times 190$.) The total luminal surface area of each segment was estimated according to rules for vertical sections, ${ }^{10}$ using the number of intersections with the epithelial-lamina propria interface $\Sigma I$, the test line length per point $1_{(\mathrm{p})}$, the number of points hitting the mucosa $\Sigma P$, and the mucosa volume $V($ mucosa $)$ : surface area $\left.=2 / 1_{(\mathrm{p})}\right)(\Sigma I / \Sigma P) / V\left({ }_{\text {mucosa }}\right)$.

Denmark) with black marks at $1 \mathrm{~cm}$ intervals, which were visible through the colonic wall, was inserted through the anus. The left colon was marked by 5 anti-mesenteric nonabsorbent sutures (Prolene 6-0, Ethicon, Norderstedt, Germany) at 4, 7, 8, 9, and $12 \mathrm{~cm}$ from the anus. By this method a time and intervention independent segment of proximal (9 to $12 \mathrm{~cm}$ ) and distal $(4$ to $7 \mathrm{~cm}$ ) colon was defined. The rats were then randomised to either a diverting colostomy (58 rats) or a sham operation ( 38 rats). In the colostomy group the colon was divided at the $8 \mathrm{~cm}$ mark and the colostomy was made by fixing the proximal and distal ends to muscle and skin by five

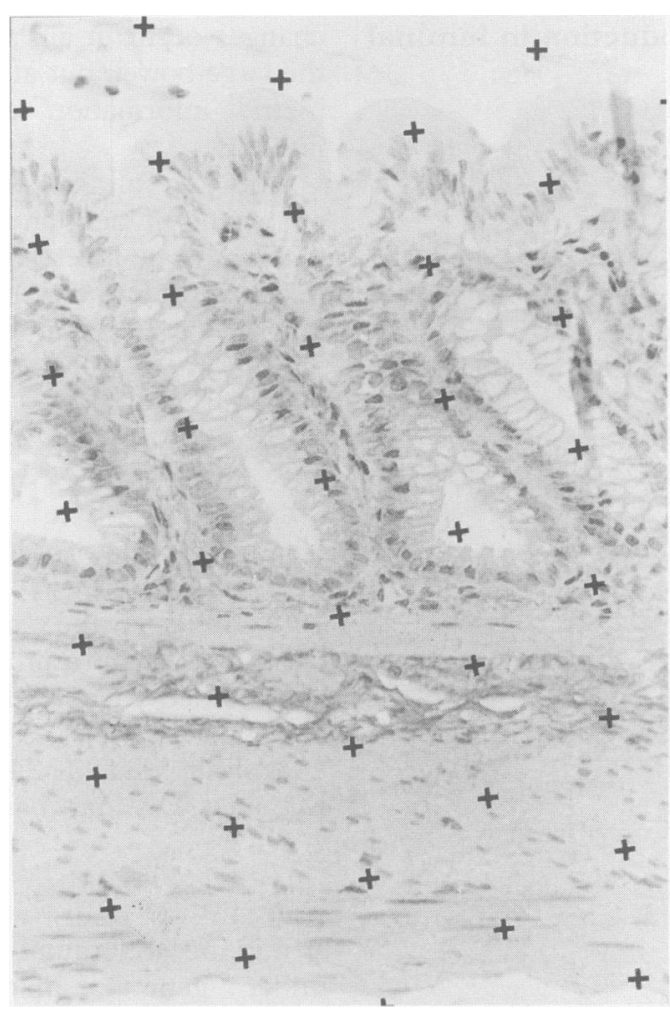

Figure 3: The point counting grid superimposed on a section of rat colonic wall after defunctioning for 12 weeks. (Van Gieson, original magnification $\times 440$.) sutures (Prolene 6-0) through stomas in the left abdominal wall. In the sham operated rats the intact colon was replaced into the abdominal cavity 15 minutes after the marking procedure. The midline incisions were closed in two layers.

\section{SAMPLING OF COLONIC SEGMENTS}

At $1,2,4$, or 12 weeks the rats were killed and the colon removed. The day 0 group (10 rats) was killed immediately after the marking procedure. After transecting the colon at the marking sutures the defined segments of proximal and distal colon were rinsed and the wet weight was determined. Each segment was cut into $5 \mathrm{~mm}$ wide rings, which were opened along their longitudinal axis (Fig 1), flattened on moist filter paper, and fixed in a $0.15 \mathrm{M}$ phosphate buffered $4 \%$ paraformaldehyde solution. After fixation for three days the specimens were randomly allocated for determination of luminal surface area, volume fractions, or epithelial mucosal proliferation (labelling index).

\section{LUMINAL SURFACE AREA}

The samples were embedded in plastic to obtain high quality histological sections with the smallest possible tissue shrinkage. Two specimens from each segment were dehydrated in alcohol, and the procedure for glycol-methacrylate application was followed (Technovit 7100, Kulzer Histo-Technik, Axel Johnson Lab System A/S). Vertical section stereology was used to determine the luminal surface area of each segment. ${ }^{12}$ This procedure requires a vertical tissue section, which is a section sliced perpendicular to the horizontal tissue plane in a random fashion. A uniform horizontal plane in the flat colon specimens is formed by the mucosal-submucosal interface. When embedding the tissue we made sure that the mucosal-submucosal interfaces of all specimens were parallel, and that each specimen was free to rotate around its vertical axis and to shift sideways in the plastic block (Fig 2). Sections ( $5 \mu \mathrm{m}$ thick) were cut parallel to the vertical axis and normal to the horizontal plane and stained with Van Gieson. The microscopic image was projected on to an orientation frame containing a test line system of cycloids and normal test points ${ }^{10}$ (Fig 2). The 'axis' of the frame was brought parallel to the vertical axis of the specimens by rotating the frame. Intersections between cycloids and the epithelial borderline to the lamina propria were counted in 16 fields of vision from each section. The total number of intersections varied from 91 to 653 . Test points hitting the mucosa were counted and used in the calculation of the total luminal surface area of each segment (Fig 2).

\section{VOLUME FRACTIONS}

Vertical plastic sections were also used for measurement of the volume fraction of the different colonic layers as well. The magnified 


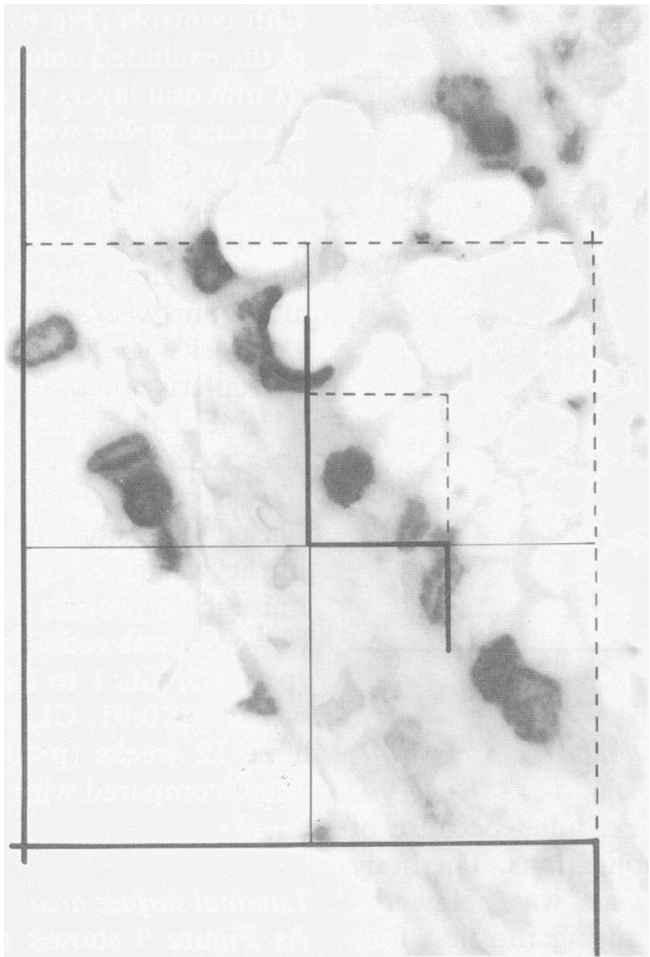

Figure 4: Bromodeoxyuridine labelling of proliferating epithelial cells in a section of colonic mucosa from a colostomy operated rat after four weeks projected onto the unbiased counting frames. All profiles completely inside the frames and all profiles with anything inside the frames are counted provided they do not in any way touch or intersect the full drawn exclusion edges or their extensions. ${ }^{14}$ (Immunohistochemical staining with anti-BrdU $M A b$; counterstain with Mayer's haematoxylin, original magnification $\times 1100$.)

microscopic image $(\times 308)$ was projected onto a point counting grid with 116 points arranged in a square pattern (Fig 3). The number of points hitting the mucosa, the submucosa, and the muscularis propria were counted. The volume fraction was calculated by dividing the point count for each layer in 12 fields of vision with the sum of point counts, which included points hitting the small amounts of serosa, mesenterical fat, or lymphoid tissue. The total number of points counted in each specimen varied from 282 to 1268 . The weight of each layer was determined by multiplying the wet weight of colonic segments with the volume fraction of each layer. The procedure was repeated at a higher magnification $(\times 616)$ on 10 randomly chosen fields to differentiate the mucosa separately into epithelium (surface and crypt cells), lamina propria, and muscularis mucosae. The total number of counted points was from 172 to 523 .

EPITHELIAI, MUCOSAL PROLIFERATION AND LABELLING INIEX

Bromodeoxyuridine (BrdU) is a pyrimidine analogue of thymidine that is incorporated into the DNA of cells in the S-phase. The nuclei of these cells can be visualised by means of an anti-BrdU monoclonal antibody and BrdU was used to label the proliferating population of epithelial mucosal cells. ${ }^{13}$ At exactly one hour before death 5'-bromo-2'-deoxyuridine $(10 \mathrm{mg} / \mathrm{ml}$ in purified water) was injected intraperitoneally into each rat in a dose of
$50 \mathrm{mg} / \mathrm{kg}$ body weight. Two specimens from each animal were wax embedded and cut in $5 \mu \mathrm{m}$ sections perpendicular to the mucosal surface. BrdU-labelled DNA was detected by antibody application (Dakopats A/S, Denmark) followed by a solution of ethylcarbazole (Sigma Immuno Chemicals, St Louis, USA) for antibody demonstration. Thus, positive stained nuclei appeared as red-brownish profiles in the sections that were weakly counterstained by Mayer's haematoxylin. The cells were counted as profiles in two dimensions and the microscopic image was projected onto two unbiased counting frames sized $100 \mathrm{~cm}^{2}$ and $6.25 \mathrm{~cm}^{2}$. Using a motordriven specimen stage we randomly chose 20 fields of vision with epithelial nuclei profiles inside the large frame and the profiles were counted according to the rules for unbiased counting ${ }^{14}$ (Fig 4). Because of the unequal number of labelled and unlabelled profiles the second were counted in the smallest frame and the total number counted varied from 94 to 335 . The unlabelled count was multiplied by 16 and the labelling index was calculated as the number of stained profiles in percentage of all profiles counted. Counting in $3 \mathrm{D}$ is the only way to obtain truly unbiased quantitative estimates of three dimensional objects, but the surface labelling technique rules out the use of thick sections required for the optical disector. ${ }^{15}$ In principle, the physical disector could have been applied, but in the present setting we did not expect to profit from this more laborious technique. 16 All stereological counting procedures were performed in a blind fashion to avoid observers bias.

\section{STATISTICS}

The groups were compared using the MannWhitney two sample test, $p$ values less than $5 \%$ were considered statistically significant, and 95\% confidence limits (CL) for differences between the means were calculated, using the normal distribution. Two labelling index values of 82 were rejected as extreme values ('outliers') according to Documenta Geigy, ${ }^{17}$ with a significance probability less than $1 \%$.

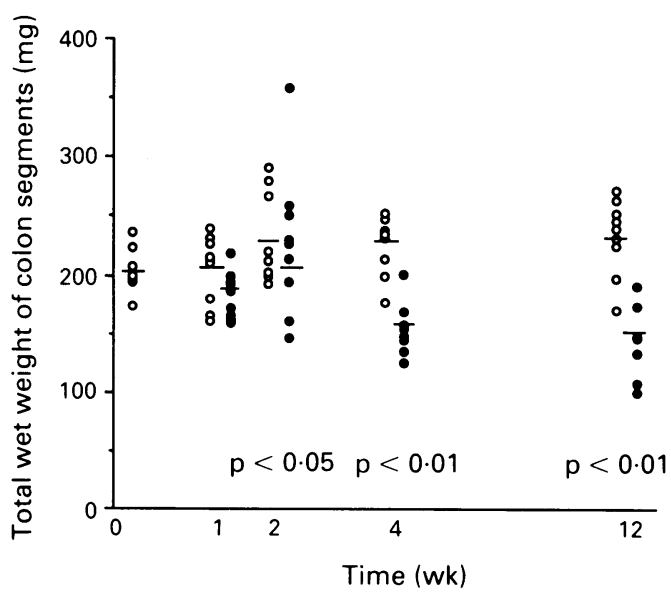

Figure 5: Total wet weight of distal colon segments at 0, 1 , 2,4 , and 12 weeks after colostomy (•) and sham operation (O) 
TABLE I Mean volume fractions of the major colonic layers (ratio: $\Sigma$ counts (layer) $/ \Sigma$ counts (total)

\begin{tabular}{|c|c|c|c|c|c|}
\hline & Day 0 & 1 Week & 2 Weeks & 4 Weeks & 12 Weeks \\
\hline \multicolumn{6}{|l|}{ Distal colon } \\
\hline $\begin{array}{l}\text { Sham } \\
\text { Colostomy }\end{array}$ & $0 \cdot 48$ & $\begin{array}{l}0 \cdot 48 \\
0 \cdot 49\end{array}$ & $\begin{array}{l}0 \cdot 53 \\
0 \cdot 46\end{array}$ & $\begin{array}{l}0.51 \\
0.45\end{array}$ & $\begin{array}{l}0.49 \\
0.52\end{array}$ \\
\hline $\begin{array}{l}\text { Submucosa: } \\
\text { Sham } \\
\text { Colostomy }\end{array}$ & $0 \cdot 15$ & $\begin{array}{l}0 \cdot 14 \\
0 \cdot 13\end{array}$ & $\begin{array}{l}0 \cdot 12 \\
0 \cdot 15\end{array}$ & $\begin{array}{l}0.14 \\
0 \cdot 16\end{array}$ & $\begin{array}{l}0 \cdot 12 \\
0 \cdot 16\end{array}$ \\
\hline Muscularis: & & & & & \\
\hline $\begin{array}{l}\text { Sham } \\
\text { Colostomy }\end{array}$ & $0 \cdot 34$ & $\begin{array}{l}0 \cdot 37 \\
0 \cdot 36\end{array}$ & $\begin{array}{l}0.31 \\
0.34\end{array}$ & $\begin{array}{l}0 \cdot 35 \\
0 \cdot 34\end{array}$ & $\begin{array}{l}0 \cdot 39 \\
0 \cdot 30\end{array}$ \\
\hline $\begin{array}{l}\text { Proximal colon } \\
\text { Mucosa: }\end{array}$ & & & & & \\
\hline $\begin{array}{l}\text { Sham } \\
\text { Colostomy }\end{array}$ & 0.50 & $\begin{array}{l}0.51 \\
0.49\end{array}$ & $\begin{array}{l}0.53 \\
0.50\end{array}$ & $\begin{array}{l}0.47 \\
0.47\end{array}$ & $\begin{array}{l}0.45 \\
0.44\end{array}$ \\
\hline Submucosa: & & & & & \\
\hline $\begin{array}{l}\text { Sham } \\
\text { Colostomy }\end{array}$ & $0 \cdot 12$ & $\begin{array}{l}0 \cdot 12 \\
0 \cdot 11\end{array}$ & $\begin{array}{l}0 \cdot 14 \\
0 \cdot 12\end{array}$ & $\begin{array}{l}0 \cdot 12 \\
0 \cdot 12\end{array}$ & $\begin{array}{l}0.14 \\
0.09\end{array}$ \\
\hline Muscularis: & & & & & \\
\hline $\begin{array}{l}\text { Sham } \\
\text { Colostomy }\end{array}$ & 0.35 & $\begin{array}{l}0.35 \\
0.36\end{array}$ & $\begin{array}{l}0.34 \\
0.32\end{array}$ & $\begin{array}{l}0.38 \\
0.38\end{array}$ & $\begin{array}{l}0.41 \\
0.41\end{array}$ \\
\hline
\end{tabular}

\section{Results}

GENERAL OBSERVATIONS

Twelve rats $(11 \%)$ were excluded because of anaesthetic or stoma complications. The body weight of the colostomy rats was below the body weight of controls during the first four weeks after surgery, but 12 weeks after surgery there was no difference between the body weight of the two groups.

\section{DEFUNCTIONED (DISTAL) COLONIC SEGMENTS}

Weight of colon and the colonic layers

The wet weight of the defunctioned colonic segments decreased throughout the observation period, and was $12 \%$ less after one week $(\mathrm{p}<0.05, \mathrm{CL} 3$ to $48 \mathrm{mg}), 7 \%$ less after two weeks ( $p=0 \cdot 5$, CL -27 to $59 \mathrm{mg}$ ), $30 \%$ less after four weeks ( $<<0.001$, CL 45 to $90 \mathrm{mg}$ ), and $36 \%$ less after 12 weeks $(p<0.001$, CL 58 to $110 \mathrm{mg}$ ) when compared with the colon of sham operated controls (Fig 5). Table I shows the volume fractions obtained by point counting. The final morphometric analysis showed that the mucosal weight decreased by $10 \%$ during the first week $(\mathrm{p}=0.05, \mathrm{CL}-1$ to $22 \mathrm{mg}$ ), by $21 \%$ after two weeks ( $<<0.05, \mathrm{CL}$ 6 to $45 \mathrm{mg}$ ), by $37 \%$ after four weeks ( $<<0.01$, CL 27 to $59 \mathrm{mg}$ ), and by $31 \%$ after 12 weeks $(\mathrm{p}<0.001, \mathrm{CL} 21$ to $48 \mathrm{mg})$ when compared

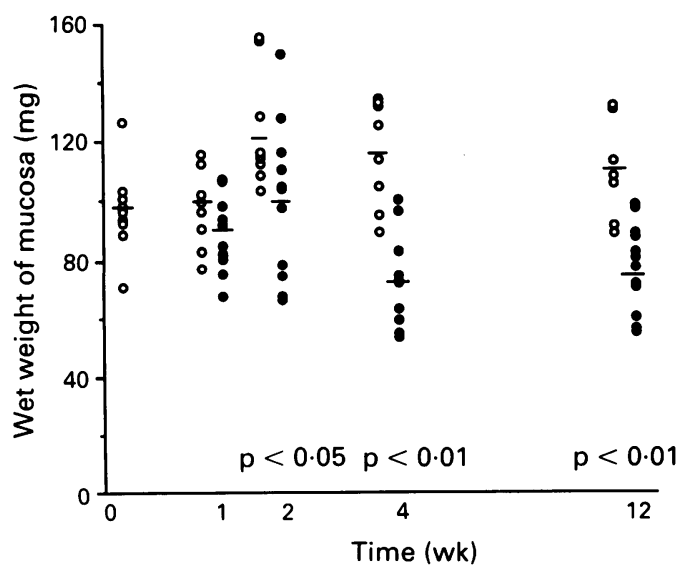

Figure 6: Weight of the mucosa of distal colon segments at $0,1,2,4$, and 12 weeks after colostomy $(\bullet)$ and sham operation $(\mathrm{O})$. with controls (Fig 6). The atrophy of mucosa in the excluded colon was related to atrophy of all mucosal layers (Table II): there was a $41 \%$ decrease in the weight of the epithelium after four weeks $(p<0.001)$ and a $48 \%$ decrease after 12 weeks $(p<0.001)$ when compared with controls. The lamina propria weight decreased by $23 \%$ after two weeks $(p<0 \cdot 05)$, by $35 \%$ after four weeks $(p<0.01)$, and by $18 \%$ after 12 weeks $(p<0.05)$, and the weight of the muscularis mucosae in defunctioned colon was $34 \%$ less after one week $(p<0.05), 35 \%$ less after four weeks $(p<0.05)$, and $34 \%$ less after 12 weeks $(p<0.05)$ compared with controls. Faecal diversion did not cause any changes in the weight of the submucosa (Fig 7). The muscularis propria of the excluded segments, however, was reduced by $17 \%$ after one week ( $\mathrm{p}<0.05, \mathrm{CL} 1$ to $24 \mathrm{mg}$ ), by $32 \%$ after four weeks ( $<<0.01, C L 12$ to $38 \mathrm{mg}$ ), and by $48 \%$ after 12 weeks ( $<0.001$, CL 29 to $55 \mathrm{mg}$ ) when compared with controls (Fig 8).

\section{Luminal surface area}

As Figure 9 shows, the total luminal surface area in the diverted group was reduced by $17 \%$ after one week $\left(\mathrm{p}=0.11, \mathrm{CL}-0.4\right.$ to $\left.2.7 \mathrm{~cm}^{2}\right)$, by $24 \%$ after two weeks $(\mathrm{p}<0.05$, CL 0.2 to $3.9 \mathrm{~cm}^{2}$ ), and by $47 \%$ after four weeks $\left(\mathrm{p}<0.01\right.$, CL 1.9 to $\left.4.8 \mathrm{~cm}^{2}\right)$ when compared with sham operated controls. No further reduction was seen from 4 to 12 weeks, at which time the difference in luminal surface area between the groups was $46 \%(p<0.001$, CL 1.7 to $4.4 \mathrm{~cm}^{2}$ ).

\section{Labelling index}

The results obtained through unbiased profile counting are interpreted as applying to real epithelial cells. This is done under the assumption that there was no significant difference in the size or shape of labelled and unlabelled cells (Fig 4). As Figure 10 shows there were no significant differences between the labelling index of colostomy groups and control groups at any point during the observation period.

\section{COLONIC SEGMENTS PROXIMAL TO THE}

\section{COLOSTOMY}

There was an increase of about $50 \mathrm{mg}$ in the wet weight of the proximal colonic segments of normal colon during the observation period. There was a comparative increase in the wet weight of the diverted groups compared with normal colon, but Table III shows, it only reached a significant value two weeks after surgery $(p<0.05)$. No differences were found at any point between the two groups in either luminal surface area or labelling index.

\section{Discussion}

This study shows a substantial atrophy of the mucosal layer in the left colon after total bowel rest. The mucosal weight of the initially defined segments of left colon decreased by 
TABLE II Difference in weight of the separate mucosal layers of distal colonic segments

\begin{tabular}{lcccc}
\hline & \multicolumn{4}{l}{ Difference (sham-colostomy) in mg at: } \\
\cline { 2 - 5 } & 1 Week & 2 Weeks & 4 Weeks & 12 Weeks \\
\hline Epithelium & $4 \cdot 6(-1$ to 11$)$ & $7 \cdot 9(-1$ to 17$)$ & $16 \cdot 2(11 \text { to } 23)^{\star \star}$ & $19(13 \text { to } 25)^{\star \star}$ \\
Lamina propria & $-0 \cdot 4(-5$ to 5$)$ & $14(2 \text { to } 26)^{\star}$ & $19 \cdot 8(10 \text { to } 30)^{\star \star}$ & $9 \cdot 4(2 \text { to } 17)^{\star}$ \\
Muscularis mucosae & $6(1 \text { to } 11)^{\star}$ & $3 \cdot 6(-2$ to 9$)$ & $7(2 \text { to } 12)^{\star}$ & $6 \cdot 5(2 \text { to } 11)^{\star}$
\end{tabular}

Values are sham-colostomy with $95 \%$ confidence limits in parentheses. $\left(\mathrm{p}<0.05\right.$; ${ }^{\star} \mathrm{p}<0.01$;

$\star \star$ colostomy compared with sham operated rats).

more than $30 \%$ after faecal diversion in four weeks, and the total surface area covered by mucosal epithelium in these segments were reduced by $50 \%$ when compared with the same intact segments of sham operated rats after four weeks. Reduction in the weight of the mucosal layer of excluded rat colon has previously been described, ${ }^{818}$ and the present data on reductions in surface area are in accordance with studies by Rijke et al and Delveaux et al showing that the number of cells per crypt decreased and that the crypt height was reduced after faecal diversion. ${ }^{79} \mathrm{We}$ found that atrophy of the mucosal layer was significant as early as two weeks after faecal diversion. These changes continued until four weeks after surgery, at which time both the mucosal weight and the surface area reached a 'steady state', as no further atrophy was detectable during the following eight weeks. Apparently the mucosal atrophy takes place mainly in the early weeks after colostomy.

The epithelium undergoes a major atrophy after faecal diversion in more than two weeks. It has previously been shown that similar changes are associated with a reduction in epithelial cell number rather than epithelial cell size. $^{8} \mathrm{We}$ found no quantitative difference, however, in the epithelial cell labelling index (proliferating cells per total epithelial cells) between colostomy and control groups. These findings suggest that the decrease in epithelial cellularity is caused by a reduction in the total number of cells undergoing proliferative activity without changes in the average life span of epithelial cells, and this decrease in the number of proliferating cells leads to a decline in the luminal surface area. Conflicting reports exist in other studies using labelling index determination for measurement of epithelial

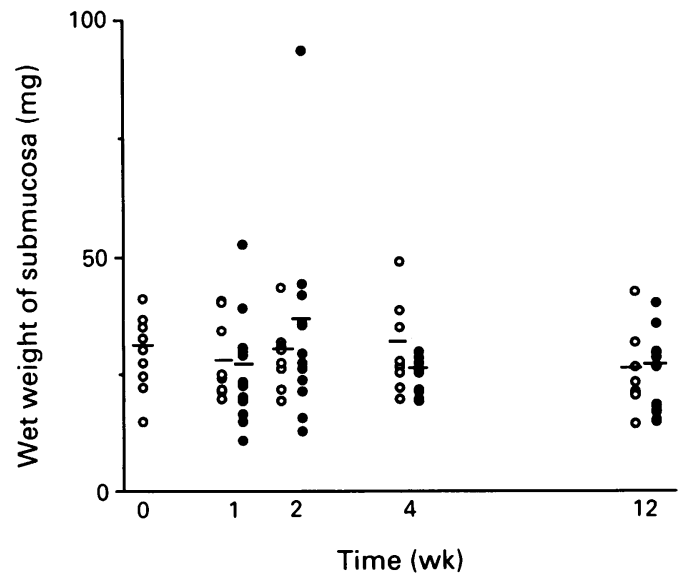

Figure 7: Weight of the submucosa of distal colon segments at $0,1,2,4$, and 12 weeks after colostomy ( $(\bullet)$ and sham operation (O).

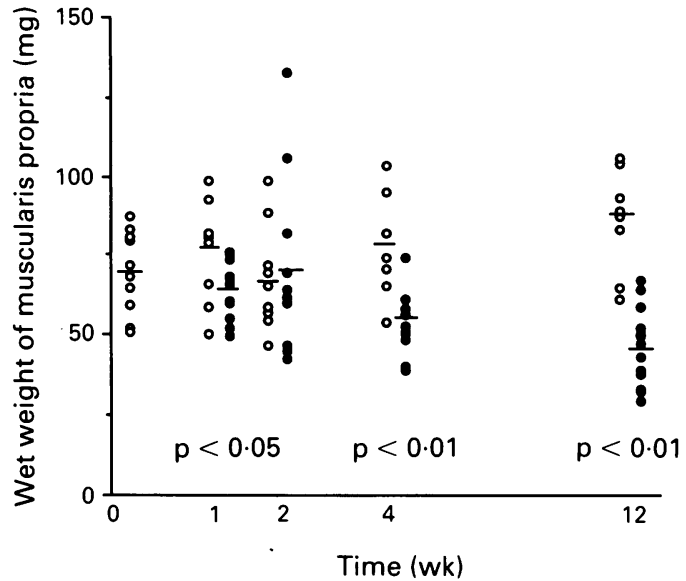

Figure 8: Weight of the muscularis propria of distal colon segments at 0, 1, 2, 4, and 12 weeks after colostomy (৫) and sham operation $(0)$.

proliferation of excluded large bowel mucosa. Some results are in accordance with this study, ${ }^{9}$ whereas others have shown a fall in the labelling index five days and three weeks after surgery. ${ }^{7}$ In this last study, however, the proliferative investigations were confined to restricted areas of each crypt. Furthermore, the quantification methods used in both studies were based on selected crypt specimens instead of uniformly sampled mucosal specimens. ${ }^{79}$

Stereological methods make it possible to obtain information about three dimensional structures based on findings made on two dimensional sections. For this information to be unbiased certain requirements must be fulfilled about the sections and the way they are prepared.$^{10}$ In this study colonic specimens were sampled uniformly from the marked segment, and sections used for quantification were chosen at random. After these requirements were fulfilled, the information obtained from the histological sections were applicable on the marked segments of distal colon in rats. Previous experimental studies on defunctioned large bowel are based on findings made on a limited number of particularly selected crypts. $^{7919}$ As uniform sampling was not used the results may consequently be biased. Furthermore, when the proliferative activity of selected crypts is calculated, these results can

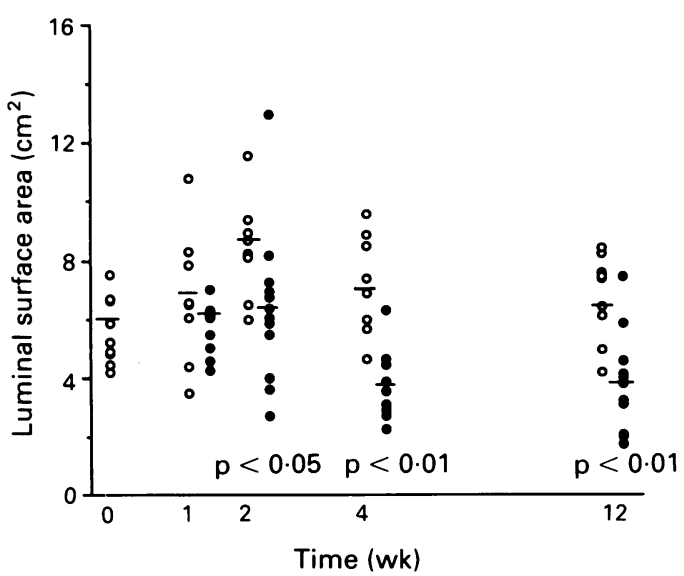

Figure 9: The luminal surface area of distal colon segments at $0,1,2,4$, and 12 weeks after colostomy ( $\bullet$ and sham operation (O). 


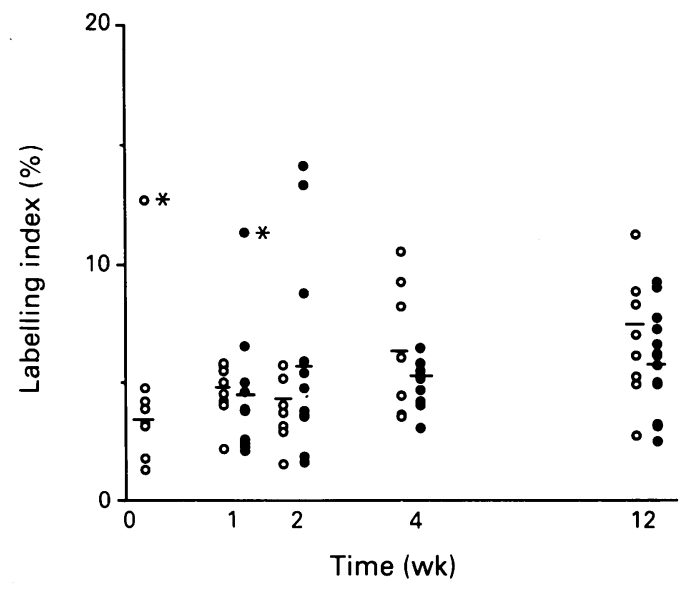

Figure 10: The labelling index of distal colon segments at $0,1,2,4$, and 12 weeks after colostomy (•) and sham operation $(0){ }^{\star}=$ outliers $)$.

only be applied to the overall colonic mucosa if it is assumed, that the number of mucosal crypts remains unchanged after faecal diversion. There are no available results that, however, support this assumption, and the appearance of the colonic mucosa after 12 weeks of defunctioning (Fig 2) suggests that deteriorations in crypt size, form, and number might occur. Changes in total crypt number and crypt morphology may occur after defunctioning of the human large bowel as well. This should be taken into consideration when results based on a few selected crypts from colonic biopsy specimens are evaluated.

Previous studies have focused on the atrophic changes occurring in the mucosa of the resting bowel. A single report in humans of considerable muscular atrophy in the rectum after many years of defunctioning suggested, however, that colonic atrophy was not restricted only to the mucosal layer. ${ }^{20}$ From our data it is evident that the atrophy also involves the external muscular layer. We found a reduction in the weight of this layer as early as one week after colostomy, and after 12 weeks the muscle weight was reduced by nearly $50 \%$ when compared with the colon of sham operated rats. A major atrophy of both the circular and longitudinal muscle layers may explain the longitudinal bowel shortening in rats fed on a low residue diet. ${ }^{21}$ Collagen constitutes about $20 \%$ of the muscular wet weight, and an important decrease in the collagen and protein synthesis in rat colon after faecal diversion has previously been reported. ${ }^{11}$ These findings by Blomquist et al suggest that atrophy in the muscularis propria of defunctioned colon is caused by a decrease in the rate by which newly formed muscular tissue replaces the old. Though the main collagen rich layer is the submucosa, which consists almost exclusively of closely interwoven collagen fibres, ${ }^{22}$ we did not find any changes in the mass of this layer even 12 weeks after exclusion. Unchanged submucosal dimensions, however, do not rule out that the structure or properties of the collagen in defunctioned colon may change.

The weight in mg of each colonic layer was calculated by multiplying the volume fraction of each layer with the reference weight, which was the wet weight of the colonic segments. The volume fractions of the mucosa and the muscularis propria were not dramatically changed during the 12 weeks of defunctioning (Table I), and the weight reductions in these layers followed the reduction in wet weight of the defunctioned segments. This illustrates that the volume fraction is a halfway result, which generally does not permit conclusions to be made about changes in the absolute amount of the structure under study, and it underlines the significance of reliable and standardised reference volumes or weights when using these stereological methods.

Intestinal growth is regulated by general and local growth factors in combination. ${ }^{23}$ In the colon of humans and rats, the short chain fatty acids derived from bacterial fermentation of luminal carbohydrate play a vital part in the colonic growth regulation, ${ }^{24}$ but the tissue is also considered to be affected by systemic factors like gastrin, enteroglucagon, epidermal growth factor, and several metabolic hormones. ${ }^{23} 25$ The degeneration of a diverted bowel is associated with a prolonged deprivation of such luminal and systemic growth factors. ${ }^{26}$ In this study we aimed to quantify experimentally the changes of the entire distal colonic wall rather than investigating the effect of specific substances on the atrophic process. A proper quantification of the atrophic changes seen in colon after faecal diversion does, however, provide a valuable basis for future studies using short chain fatty acid installation or systemic treatment with potentially growth stimulating substances.

In conclusion, interruption of normal anatomical continuity by a diverting colostomy entails fundamental changes in the intraluminal conditions and the biomechanical requirements of the large intestine. The presented data show radical morphological changes related to the mucosa and the muscular layers of the bowel wall after defunctioning the left colon.

We thank Mrs A Larsen for her skilled technical assistance. The study was supported by Novo Nordisk A/S.

TABLE III Proximal colonic segments. Difference in total wet weight and weight of separate colonic wall layers between groups

\begin{tabular}{llllr}
\hline & \multicolumn{2}{l}{ Difference (sham-colostomy) in mg at: } \\
\cline { 2 - 5 } & 1 Week & 2 Weeks & 4 Weeks & 12 Weeks \\
\hline Total wet weight & $25(-17$ to 67$)$ & $108 \cdot 5(16 \text { to } 201)^{\star}$ & $39 \cdot 6(-19$ to 98$)$ & $27 \cdot 3(-32$ to 86$)$ \\
Mucosa & $8 \cdot 6(-20$ to 37$)$ & $48 \cdot 2(-11$ to 107$)$ & $20 \cdot 4(-12$ to 53$)$ & $13 \cdot 3(-24$ to 51$)$ \\
Submucosa & $4 \cdot 5(-2$ to 11$)$ & $14 \cdot 7(-2$ to 32$)$ & $6 \cdot 7(-3$ to 17$)$ & $0 \cdot 9(-15$ to 17$)$ \\
Muscularis propria & $7 \cdot 5(-13$ to 28$)$ & $26 \cdot 2(-4$ to 56$)$ & $12 \cdot 7(-17$ to 43$)$ & $-0 \cdot 6(-29$ to 28$)$ \\
\hline
\end{tabular}

Values are colostomy-sham with $95 \%$ confidence limits in parentheses. ( $<<0.05$; $^{\star}$ colostomy compared with sham operated rats). 
1 Foster ME, Leaper DJ, Williamson RCN. Changing patterns in colostomy closure: the Bristol experience patterns in colostomy closure: the B

2 Parks SE, Hastings PR. Complications of colostomy closure. Am f Surg 1985; 149: 672-5.

3 Pearce NW, Scott SD, Karran SJ. Timing and method of reversal of Hartmann's procedure. Br $\mathcal{f}$ Surg 1992; 79: 839-41.

4 Appleton GVN, Williamson RCN. Hypoplasia of defunctioned rectum [Abstract]. Br $\mathcal{F}$ Surg 1989; 76: 787-9.

5 Ryan GP, Dudrick SJ, Copeland EM, Johnson LR. Effects of various diets on colonic growth in rats. Gastroenterology 1979; 77: 658-63.

6 Stragand JJ, Hagemann RF. Effect of lumenal contents on colonic cell replacement. Am f Physiol 1977; 233: 208-11.

7 Delvaux G, Caes F, Willems G. Influence of a diverting colostomy on epithelial cell proliferation in the colon of colostomy on epithelial cell prolife.

8 Terpstra OT, Dahl EP, Williamson RCN, Ross JS, Malt RA. Colostomy closure promotes cell proliferation and dimethylhydrazine-induced carcinogenesis in rat distal colon. Gastroenterology 1981; 81: 475-80.

9 Rijke RPC, Gart R, Langendoen NJ. Epithelial cell kinetics in the descending colon of the rat. The effect of experimental bypass. Virchows Arch 1979; 31: 23-30.

10 Gundersen HJG, Bendtsen TF, Korbo L, Marcussen N, Moller A, Nielsen $\mathrm{K}$, et al. Some new, simple and efficient stereological methods and their use in pathological research and diagnosis. APMIS 1988; 96: 379-94.

11 Blomquist $\mathrm{P}$, Jiborn $\mathrm{H}$, Zederfeldt $\mathrm{B}$. Effect of diverting colostomy on collagen metabolism in the colonic wall. $\mathrm{Am}$ folostomy on collagen m 1985 ; 149: $330-3$.

12 Baddeley AJ, Gundersen HJG, Cruz-Orive LM. Estimation of surface area from vertical sections. $\mathcal{F}$ Microsc 1986; 142: 259-76.

13 Williams ED, Wynford-Thomas D. Use of bromodeoxyuridine for cell kinetic studies in intact animals. Cell Tissue Kinet 1986; 19: 179-82.

14 Gundersen HJG. Notes on the estimation of the numerica density of arbitrary profiles: the edge effect. $\mathcal{F}$ Microsc 1977; 111: 219-23.

15 Gundersen HJG. Stereology of arbitrary particles. A review of unbiased number and size estimators and the presentation of some new ones, in memory of William R tion of some new ones, in memory

16 Sterio DC. The unbiased estimation of number and size of arbitary particles using the disector. 7 Microsc 1984; 134: arbitary par

17 Documenta Geigy, Scientific Tables. Basel: JR Geigy SA, 1970: 170-1.

18 Rainey JB, Davies PW, Bristol JB, Williamson RCN Adaptation and carcinogenesis in defunctioned rat colon: divergent effects of faeces and bile acids. $\mathrm{Br} \mathcal{F}$ Cancer 1983; 48: 477-84.

19 Bristol JB, Ghatei MA, Smith JHF, Bloom SR, Williamson $\mathrm{RCN}$. Elevated plasma enteroglucagon alone fails to alter distal colonic carcinogenesis in rats. Gastroenterology 1987 ; 92: 617-24.

20 Shaw-Dunn J, Wright $R$. Changes in the large intestine after 35 years of defunctioning by ileostomy. Ann R Coll Surg Engl 1981; 63: 210-1.

21 Udén P, Blomquist P, Jiborn H, Zederfeldt B. Impact of long-term relative bowel rest on conditions for colonic surgery. Am ₹ Surg 1988; 156: 381-5.

22 Komuro $T$. The lattice arrangement of the collagen fibres in the submucosa of the rat small intestine: scanning electron microscopy. Cell Tissue Res 1988; 251: 117-21.

23 Johnson LR. Regulation of gastrointestinal growth. In Johnson LR, ed. Physiology of the gastrointestinal tract. New York: Raven Press, 1987: 301-33.

24 Kripke SA, Fox AD, Berman JM, Settle RG, Rombeau JL. Stimulation of intestinal mucosal growth with intracolonic infusion of short-chain fatty acids. FPEN $\mathcal{F}$ Parent Enteral infusion of short-chain 1989 ; 13: 109-16.

25 Dowling RH. Cellular and molecular basis of intestinal and pancreatic adaptation. Scand $\mathcal{F}$ Gastroenterol Suppl 1992; 193: $64-7$

26 Bristol JB, Williamson RCN. Large bowel growth. Scand $\mathcal{f}$ Gastroenterol 1982; 19: 25-34. 